\title{
Conceptual Design Shop: A Tool for Rapid Airframe Structural Modeling
}

\author{
Brian H. Mason* and Jesse R. Quinlan ${ }^{\dagger}$ \\ NASA Langley Research Center, Hampton, VA, 23681-2199
}

This paper presents an innovative approach to rapidly generate finite element (FE) models of a complete airframe for a variety of airframe concepts. The current implementation of this software includes all airfoil surfaces and the fuselage, and is limited to FE modeling of low-wing designs with T-tails or twin tails. This tool, called the Conceptual Design Shop (CDS), was developed using the PATRAN command language (PCL) within the PATRAN finite element modeling software. CDS is an attempt to fill a gap in current finite element modeling software to automatically connect wings and tails to the fuselage in airframe models. The CDS software is demonstrated on two airframe designs: a generic transport aircraft and an advanced aircraft design with a boundary-layer ingestion engine.

\section{Introduction}

\section{A. Motivation and Background}

Modern computers are capable of solving large scientific problems very quickly. For example, a typical finite element (FE) analysis with a few hundred degrees of freedom can be solved in a matter of minutes on a desktop workstation. Unfortunately, generation of a complete airframe FE model is typically a labor-intensive, manual process. Most currently-available software for automated FE modeling only works with individual aircraft components such as the wing and fuselage (Ref. 1 to 3). One of the difficulties with automated generation of an airframe FE model is the complicated wing/body interfaces between airfoil surfaces and the fuselage. To deal with mesh incongruity issues at these wing/body interfaces, other tools have been developed that use constraints or glue elements to connect components (Ref. 4). Additional efforts are underway to automate generation and interfaces between multiple airframe components by applying merge algorithms to create congruent meshes at the wing/body interfaces (Ref. 5 to 7), but these are limited to only a few wing/body interface concepts or rely upon an external computer-aided design (CAD) tool to generate the geometry. Geometry exported from a CAD tool is often difficult to import into a FE meshing tool, and the file formats used by CAD tools do not include information to identify a given geometric surface (for example a wing upper cover, a fuselage, or a vertical tail). Without this "intelligence” to associate a surface with a given aircraft component, it is very difficult to add internal structures and interfaces within a FE code and hence, generate an adequate FE mesh.

This paper presents an innovative approach to rapidly generate FE models of a complete airframe for a variety of airframe concepts. The current implementation of this software includes all airfoil surfaces and the fuselage, but is limited to complete FE modeling of low-wing designs with T-tails or twin tails. This tool, called the Conceptual Design Shop (CDS), was developed

\footnotetext{
${ }^{*}$ Research Aerospace Engineer, Durability and Damage Tolerance Branch, Senior Member AIAA

${ }^{\dagger}$ Aerospace Engineer, Aeronautics Systems Analysis Branch, Member AIAA
} 
using the PATRAN command language (PCL) within the PATRAN ${ }^{\ddagger}$ FE modeling software (Ref. 8). In this tool, the outer mold line geometry (OML) of an airframe is sliced into three- or foursided surfaces within the PATRAN FE modeling software. The isometric meshing routines within PATRAN work very well with these sliced surfaces, and the software has been developed to avoid creating surfaces that are not meshable with isometric routines (surfaces with more than four sides). PCL was selected due to the programmer's 27 years of experience with PATRAN and because of PATRAN's strong coupling to the MSC/NASTRAN (Ref. 9) FE solver, which includes the aeroelastic analysis capability desired by the projects CDS supports.

This paper discusses version 2.0 of the CDS software. The software was initially developed in 2006 and generated FE models only of wing components (as discussed in Ref. 3). The CDS software was successfully used in 2015 to generate geometry for two Cessna airframes for analytical correlation with a set of impact drop tests (Ref. 10). The considerable time required to prepare the CDS geometry for FE meshing demonstrated the need for improvement of the CDS 1.0 software. The effort required to generate the models of the Cessna airframes inspired the update of CDS to meet conceptual design study deliverables for current NASA programs.

\section{B. Purpose and Contents}

The purpose of this paper is to present a new tool for automated structural modeling of an airframe. This tool is intended for use in rapid generation of conceptual aircraft designs; however, the tool can also be used to significantly reduce analysis time for more detailed models by generating the basic, meshable geometry, which can then be modified and improved by an experienced structural designer to include additional design details.

This paper is organized into sections. Section II describes the main functions of the software - parameter definition, geometry generation, FE meshing, and analysis code export. In Section III, examples of two aircraft designs are described. Limitations of the software and future work are discussed in Section IV. A summary of the modeling techniques used in the paper and the conclusions of the two design studies are presented in Section V.

\section{Model Geometry and Loads}

In this section, the process used by CDS to generate the airframe FE model is described. In PATRAN, CDS is executed with either a text-based session file or with a graphical userinterface (GUI) built in PATRAN PCL. The process executed by the session file or the GUI is shown in Figure 1. First the input parameters describing the airframe are defined. These parameters are described in section II.A below. Next, a new PATRAN database is created and some basic graphics preferences are set. Airframe geometry is created using three PCL functions (detect interfaces, generate geometry, and break geometry) which are described in section II.B below. Generation of the FE mesh is described in section II.C. Finally, output of the FE model to a static or aeroelastic analysis deck is described in section II.D.

\footnotetext{
‡ The use of trademarks or names of manufacturers in this report is for accurate reporting and does not constitute an official endorsement, either expressed or implied, of such products or manufacturers by the National Aeronautics and Space Administration.
} 


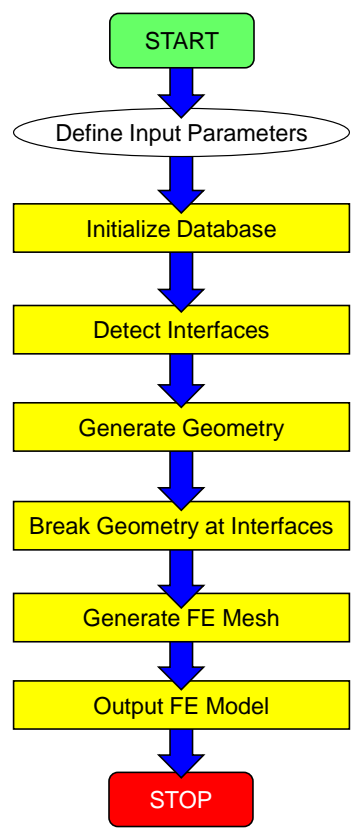

Figure 1. Functional flow diagram for CDS.

\section{A. Input Data for Analytical Models}

The CDS software uses planform geometry variables to define the wing and tail geometry in the airframe model. An example of the planform variables is presented in Table 1. These variables are stored in a set of global variables within the software. The planform variables are defined either at the beginning of the session file or as text values within a GUI dialog box. The geometry of the fuselage is stored as an array of ring frame axial locations and cross-sectional points to define the shape of the ring frame. Fuselage and engine/nacelle parameters are currently input into the software through a text file.

Table 1. Input parameters for generic subsonic transport design.

\begin{tabular}{|c|c|c|c|}
\hline Parameter & Wing & Horizontal Tail & Vertical Tail \\
\hline Surface Area (sq. in.) & 195,000 & 32,700 & 31,000 \\
\hline Aspect Ratio & 10.300 & 6.080 & 1.500 \\
\hline Spanwise Break (\%) & 37.400 & N/A & N/A \\
\hline Taper Ratio at Break (\%) & 0.507 & N/A & N/A \\
\hline Taper Ratio at Tip (\%) & 0.125 & 0.202 & 0.800 \\
\hline Dihedral Angle at Root (deg.) & 4.187 & 6.000 & 0.000 \\
\hline Dihedral Angle at Tip (deg.) & 4.187 & N/A & N/A \\
\hline Sweep at Root Quarter-Chord (deg.) & 28.336 & 30.140 & 33.200 \\
\hline Sweep at Break Quarter-Chord (deg.) & 28.336 & N/A & N/A \\
\hline Forward Spar Location (\% Chord) & 15.000 & 23.800 & 30.000 \\
\hline Aft Spar Location (\% Chord) & 80.000 & 65.370 & 66.750 \\
\hline Thickness Ratio (\% Chord) & 0.120 & 0.120 & 0.120 \\
\hline X Location of Leading Edge Root (in.) & 535.500 & 1381.000 & 1250.000 \\
\hline Z Location of Leading Edge Root (in.) & -9.200 & 270.000 & 90.000 \\
\hline Number of Inboard Bays & 8 & 5 & 5 \\
\hline Number of Outboard Bays & 19 & N/A & N/A \\
\hline
\end{tabular}




\section{B. Geometry for Analytical Models}

The PATRAN software does not permit modification of an existing geometric entity. The modify command in PATRAN actually creates a new entity based on the entity that is selected to be modified. Because of this modeling approach, a special function is used in CDS to determine wing/body interface data based on the input parameters before the initial geometry is created. Currently this interface detection function performs three operations: (1) calculates axial locations for two bulkheads in the fuselage that line up with the forward and aft spars in the main wing, (2) calculates similar bulkhead locations for the spars in the vertical fin, and (3) determines the type of empennage as defined by the input parameters ( $\mathrm{T}$-tail, twin-tail, or conventional tail). Further enhancement of this function is planned, including automatic correction of bad input parameters (for example, if the parameters define the wing location to be completely outside the fuselage).

In CDS, the airframe geometry is created from geometric surfaces on a component-bycomponent basis. First, planform surfaces are created, as shown in Figure 2 (the wing is green and the horizontal tail is red). These surfaces are used to define aerodynamic doublet-lattice surfaces (yellow quadrilaterals in Figure 2) for MSC/NASTRAN's aeroelastic analysis deck. Next, outer mold line (OML) geometry is created, as shown in Figure 3. The OML geometry is further sliced into subcomponents as shown in Figure 4. The wing and tails are sliced at rib and spar interfaces. The fuselage is sliced at rib, bulkhead, and floor interfaces. Additional surfaces representing ribs, spars, floor, bulkheads, frames, and the floor are created during this process.

A third function is used to create surfaces at the wing/body interfaces. The airfoil surfaces (wing and tails) are sliced at their fuselage interface. The fuselage is sliced at the wing box for the airfoil surfaces. The fuselage is not sliced at the leading and trailing edges of the airfoil surfaces due to the complexity of that interface and due to the fact that the trailing edge (and occasionally leading edge) of an airfoil surface is usually a movable control surface


Figure 2. Planform geometry of generic subsonic transport design (half-symmetry). 


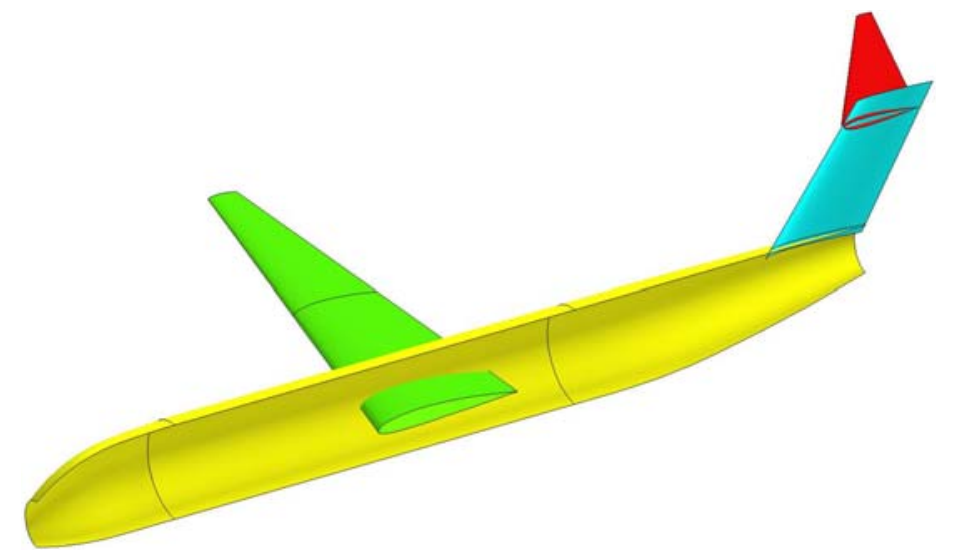

Figure 3. Outer mold line geometry of generic subsonic transport design (half-symmetry).

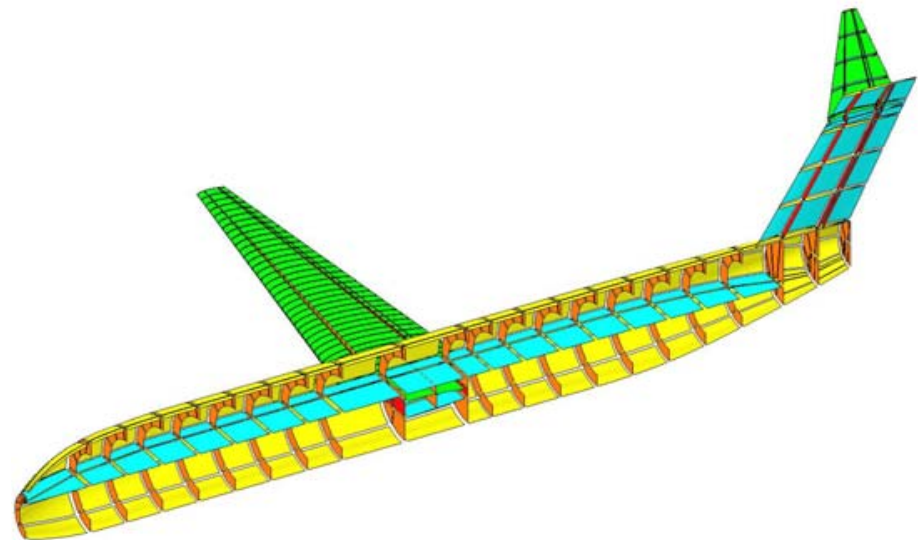

Figure 4. Meshable geometry of generic subsonic transport design (half-symmetry).

\section{Meshing of Analytical Models}

The CDS software enables automated meshing of the sliced surface airframe geometry. These three- and four-sided surfaces are meshed using PATRAN's isoparametric meshing routines using a user-defined set of mesh seeds. CDS uses a minimum of three elements through the width of all ribs, spars, and fuselage frames in order to properly model bending behavior of those components. While PATRAN has the capability of meshing surfaces with five or more edges, such surfaces can generate poor elements (triangles and elements with poor aspect ratios), and CDS was developed specifically to avoid generating such surfaces. Each meshed surface is assigned an individual section property card with a user-defined thickness and a default material (using isotropic aluminum properties).

As a check of the robustness of the CDS automated meshing capabilities, FE models of two aircraft designs have been generated and are presented in this paper. The first design is a generic transport aircraft, similar to a Boeing 757-200, as shown in Figure 5. The transport design is used to evaluate the accuracy of the NASTRAN aeroelastic analysis results by comparison with results from a simpler elliptical static distribution on the wing. The second design is a Singleaisle Turboelectric AiRCraft with Aft Boundary Layer propulsion (STARC-ABL) aircraft, as shown in Figure 6. Note that the STARC-ABL design in Figure 6 includes a boundary layer ingestion (BLI) engine aft of the vertical tail which is connected to the rest of the airframe with top and bottom struts. CDS is used to perform a concept evaluation for STARC-ABL by 
comparison of sized weights for two STARC-ABL concepts with different BLI engine mounts, with a baseline concept without the BLI engine.

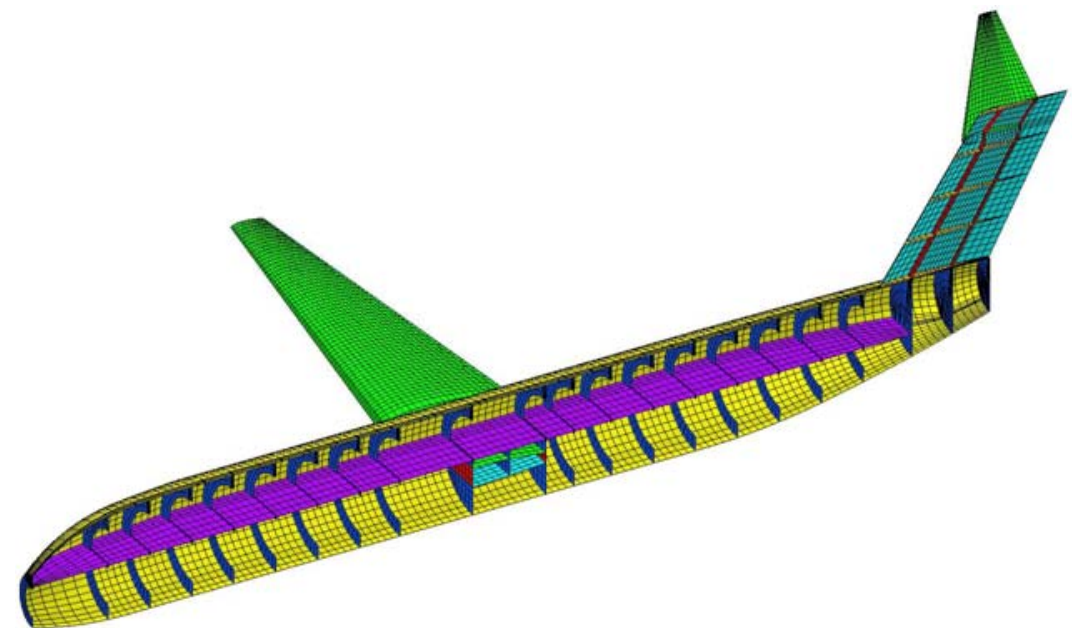

Figure 5. FE model of generic subsonic transport design (half-symmetry).

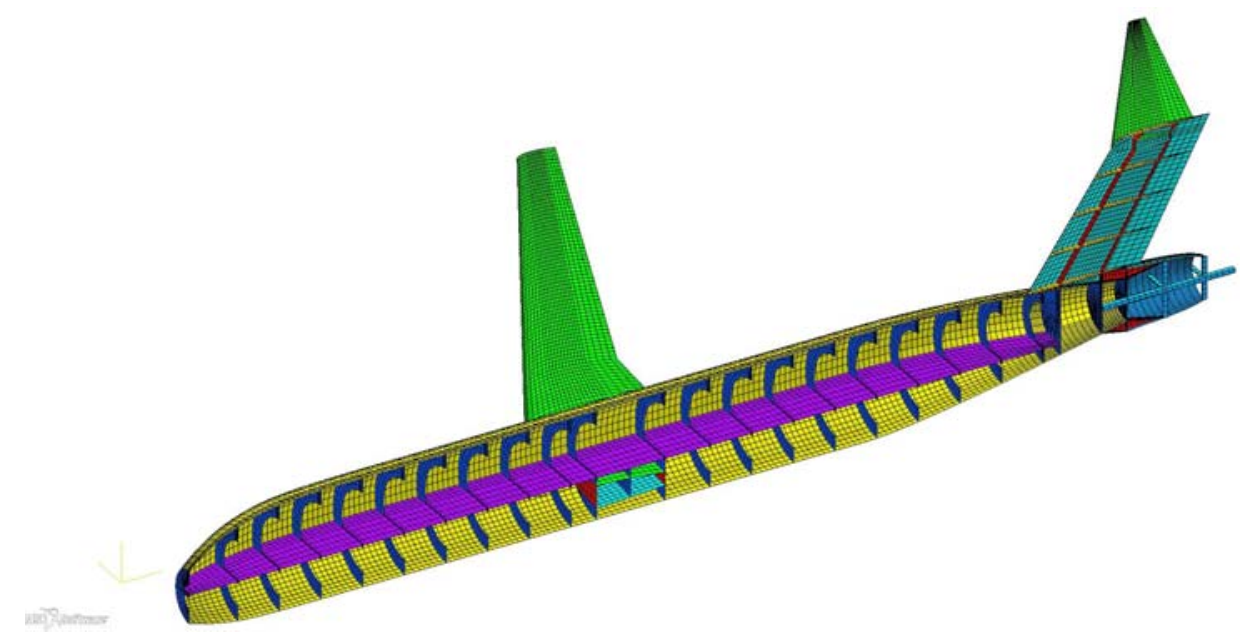

Figure 6. FE model of STARC-ABL design (half-symmetry).

\section{Analysis Deck Export for the Analytical Models}

After the FE model is meshed, the user can export the model to a FE analysis deck using PATRAN's GUI or using one of two special CDS functions. The first CDS function generates a MSC/NASTRAN deck for linear static analysis. The load cases for this deck include symmetry and rigid body boundary conditions (shown as red diamonds in Figure 7) and an elliptical wing loading (Ref. 11, shown in Figure 8) on the forward spar of the main wing. The total applied elliptical load represents the user-defined gross take-off weight (GTOW) which is multiplied by +2.5-g and -1.0-g in two load cases, to represent a maximum climb and maximum dive maneuver, respectively. CDS also computes the volume of a fuel tank between each rib and uses this volume distribution to apply a fuel weight distribution on the bottom of the spars (shown as purple triangles in Figure 8). 


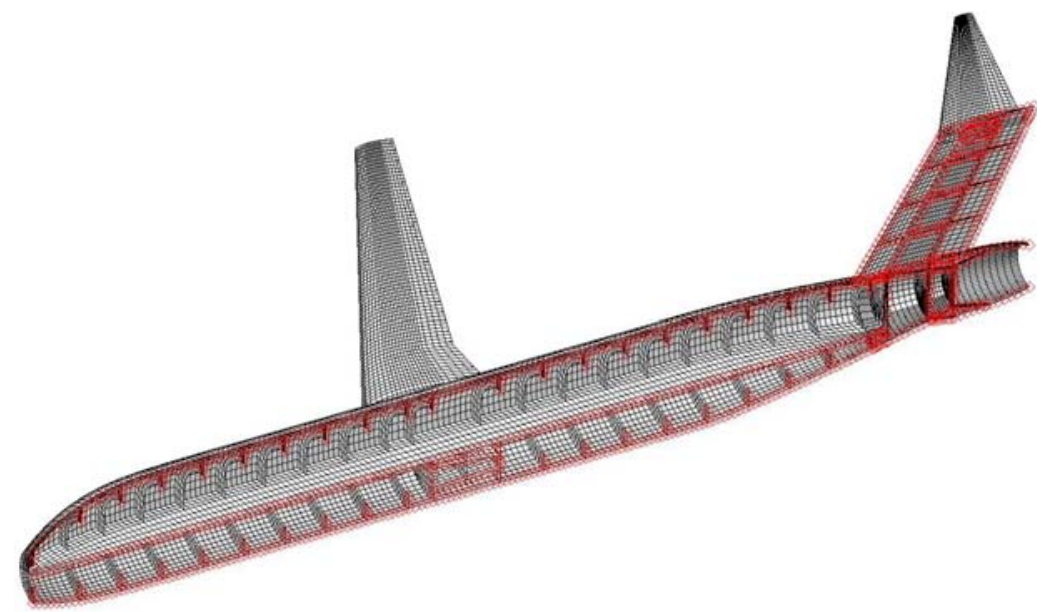

Figure 7. Symmetry boundary conditions on STARC-ABL design (half-symmetry).

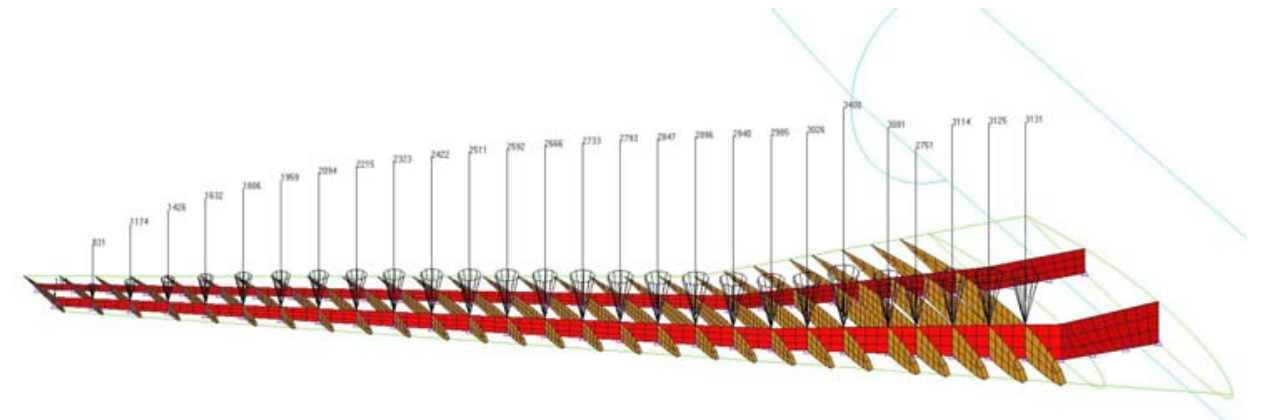

Figure 8. Elliptical load and fuel weight distribution on STARC-ABL wing (half-symmetry).

The second CDS analysis deck export function generates a MSC/NASTRAN aeroelastic analysis deck. This function uses the planform surfaces to create aerodynamic doublet-lattice panels (CAERO1 and AELIST cards) to compute the aerodynamic forces. Nodes on the upper covers of the airfoil surfaces are automatically identified by CDS (SET1 cards) and associated with the aerodynamic panels using SPLINE4 cards. Cards to define the trim loading conditions (TRIM, AEROS, and PAERO1) and the airfoil downwash angles (DMI cards for the W2GJ matrices) are also generated. Downwash angles are computed at each spanwise and chordwise location as the slope of the mean camber line of the airfoil and the incidence angle of the wing. Three typical trim conditions (Ref. 7) are considered in the aeroelastic analysis deck: $+2.5-\mathrm{g}$ maximum climb maneuver, -1.0-g maximum dive maneuver, and 1.0-g cruise flight with a fuselage pressurization case (representing 1.33 times sea level atmospheric pressure).

\section{Evaluation of Analytical Modeling Methods}

In this section, two evaluation cases for CDS are discussed. First, results from an aeroelastic analysis of a generic subsonic transport are compared to a static analysis with an elliptical wing loading. The second evaluation case is a comparison of three tail section concepts for the STARC-ABL aircraft.

\section{A. Evaluation of Aeroelastic Loading with Generic Subsonic Aircraft}

For the generic transport design, evaluation of the MSC/NASTRAN aeroelastic model is accomplished by comparison with a static model using an elliptical load distribution. For this 
comparison, only one load condition was needed; therfore the 2.5-g maneuver climb was selected as the loading condition on both models. The total aircraft weight is $160,000 \mathrm{lb}$ with a center of gravity at $720.3 \mathrm{in}$. from the nose. The MSC/NASTRAN aeroelastic analysis calculates the tail-on neutral point of the aircraft at 721.0 in. from the nose. Because the center of gravity is forward of the neutral point, the aircraft is longitudinally stable. In Figures 9 and 10, deformed plots of the static and aeroelastic models are presented. The maximum wing tip deflection is $34.0 \mathrm{in.}$ and $31.1 \mathrm{in}$. for the static and aeroelastic models, respectively. The maximum deflection of the aeroelastic wing is $8.6 \%$ less than the static model with the simplified elliptical load distribution, which is considered to be good agreement. The aeroelastic wing deflection is lower because some of the lift on the aircraft is provided by the horizontal tail in the aeroelastic model. Note that aeroelastic forces are computed within MSC/NASTRAN and applied to the tail to trim the aircraft in Figure 10, but the static loading in Figure 9 is only applied to the main wing.

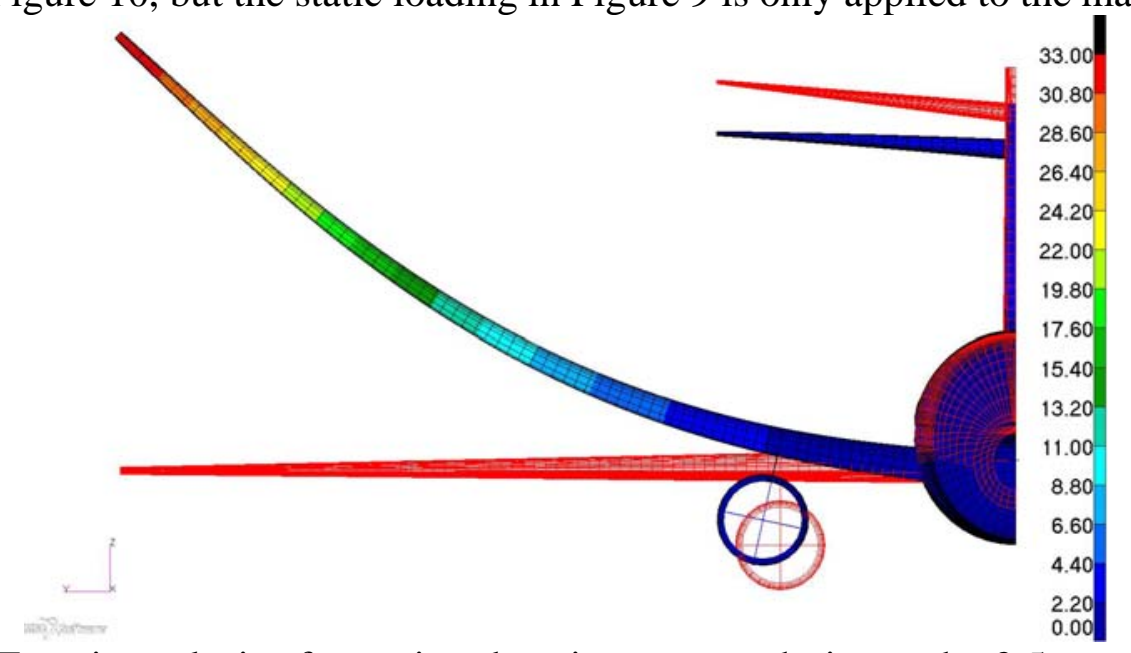

Figure 9. FE static analysis of generic subsonic transport design under 2.5-g maneuver load (half-symmetry, displacements magnified by 10 ).

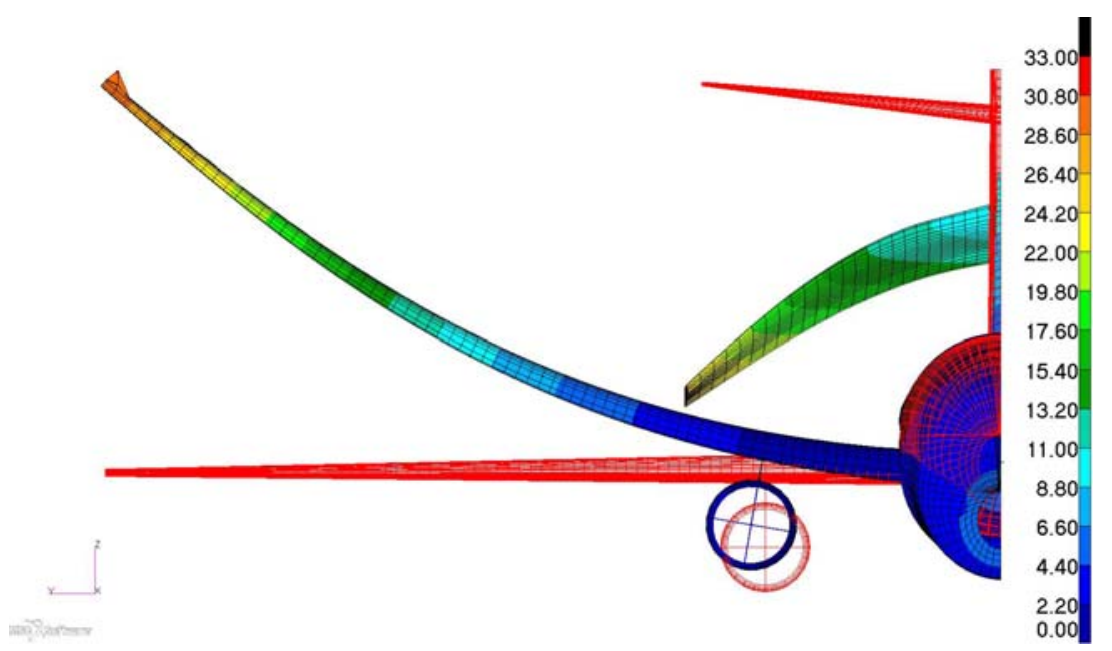

Figure 10. FE aerolastic analysis of generic subsonic transport design under 2.5-g maneuver load (half-symmetry, displacements magnified by 10). 


\section{B. Comparison of Alternative Tail Designs for STARC-ABL}

For the STARC-ABL design, three concepts with different aft fuselage sections were generated in CDS. The first concept (\#0, as shown in Figure 11) is a baseline transport aircraft concept. In the second concept (\#1, as shown in Figure 12), a BLI electric engine, also called a tail cone turbine (TCT), is attached to the aft end of the fuselage. For the third concept (\#2, as shown in Figure 13), the aft fuselage is narrowed to $60 \%$ of the diameter of concept \#1, and the T-tail assembly is moved forward 24 in.

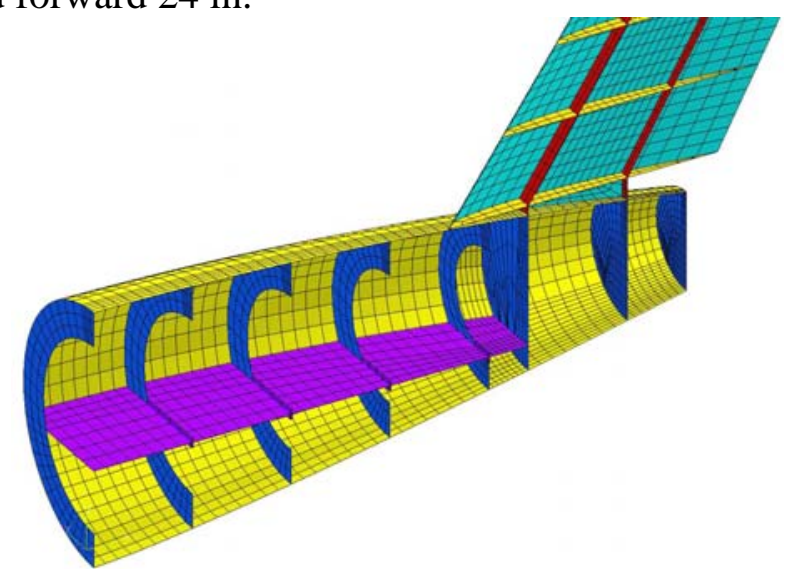

Figure 11. STARC-ABL concept $\# 0$ - baseline fuselage without TCT

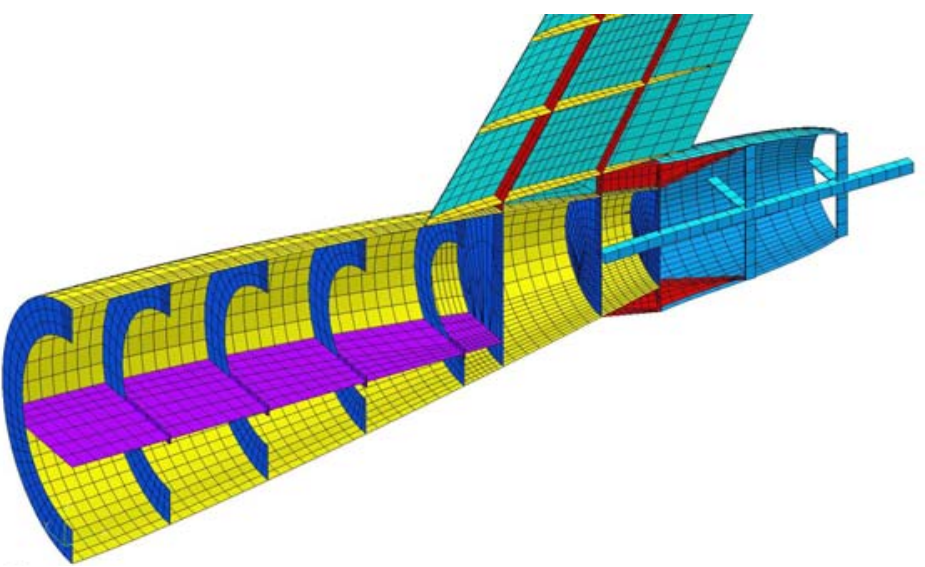

Figure 12. STARC-ABL concept \#1 - baseline fuselage with TCT



Figure 13. STARC-ABL concept \#2 - narrowed aft fuselage with TCT. 
These three concepts were analyzed using the MSC/NASTRAN aeroelasticity analysis software. Three flight conditions were considered: $1.0-\mathrm{g}$ cruise at 37,000 ft. altitude with a fuselage pressure load, 2.5-g climb maneuver at 10,000 ft. altitude, and -1.0-g dive maneuver at $10,000 \mathrm{ft}$. altitude. Structural sizing was performed for each concept using the Hypersizer software (Ref. 12) subjected to strength, buckling, and crippling constraints. The wing and fuselage were sized as aluminum 2024 panels with aluminum 7075 bolted angle stiffeners. The fuselage ring frames were sized as aluminum honeycomb panels. For each concept, at least three sizing iterations between Hypersizer and MSC/NASTRAN (to update the element-level forces) were performed, and convergence of the sizing process was defined as the point at which the weight change from one cycle to the next was less than $50 \mathrm{lb}$. Although finite element model generation was automated in CDS, setting up the Hypersizer sizing study was a manual process. An Excel-based tool was used to extract the sizing results from Hypersizer; this Excel tool could be used to set up the Hypersizer sizing process at a future date.

Table 2. Weight comparisons for three STARC-ABL concepts.

\begin{tabular}{|l|r|r|r|}
\hline \multicolumn{1}{|c|}{ Component } & Concept \#0 & Concept \#1 & Concept \#2 \\
\hline Structural Weight Forward Fuselage (lb) & 23,265 & 24,025 & 23,009 \\
\hline Structural Weight Wing (lb) & 10,141 & 10,177 & 11,188 \\
\hline Structural Weight Aft Fuselage (lb) & 6,608 & 6,535 & 5,020 \\
\hline Structural Weight Vertical Tail (lb) & 2,681 & 3,237 & 3,429 \\
\hline Structural Weight Horizontal Tail (lb) & 5,901 & 7,387 & 6.077 \\
\hline Structural Weight TCT Mount (lb) & 0 & 114 & 163 \\
\hline Fuel (lb) & 24,330 & 24,330 & 24,330 \\
\hline Wing Landing Gear (lb) & 3,279 & 3,279 & 3,279 \\
\hline Passenger + Cockpit + Controls (lb) & 56,845 & 56,845 & 56,845 \\
\hline Cockpit + Nose Landing Gear (lb) & 3,618 & 3,618 & 3,618 \\
\hline TCT (lb) & 0 & 4,437 & 4,437 \\
\hline 3 Engines (lb) & 8,855 & 8,855 & 8,855 \\
\hline GTOW (lb) & $\mathbf{1 4 5 , 5 2 4}$ & $\mathbf{1 5 2 , 0 1 6}$ & $\mathbf{1 5 0 , 2 4 9}$ \\
\hline Delta Weight - Structural (lb) & & 2,056 & $\mathbf{2 0 9}$ \\
Delta Weight - GTOW (lb) & & 6,493 & 4,726
\end{tabular}

Table 3. Aerodynamic parameters for trim at 1.0-g cruise.

\begin{tabular}{|l|r|r|r|}
\hline \multicolumn{1}{|c|}{ Component } & Concept \#0 & Concept \#1 & Concept \#2 \\
\hline CG - x (from nose) (in.) & 737.4 & 768.9 & 731.0 \\
\hline Tail-On Neutral Point (in.) & 762.7 & 762.7 & 764.5 \\
\hline Static Margin (\%) & $15.3 \%$ & $-3.8 \%$ & $20.3 \%$ \\
\hline Angle of Attack (1-g Trim, deg) & 4.07 & 4.14 & 5.03 \\
\hline Elevator Deflection (1-g Trim, deg) & -49.48 & -58.17 & -56.88 \\
\hline
\end{tabular}


Table 4. Control surface parameters

\begin{tabular}{|l|r|r|r|}
\hline \multicolumn{1}{|c|}{ Component } & Concept \#0 & Concept \#1 & Concept \#2 \\
\hline S, Wing Area (sq in) & 187,360 & 187,360 & 187,360 \\
\hline Sh, Horizontal Tail Area (sq in) & 35,637 & 35,637 & 35,637 \\
\hline Sv, Vertical Tail Area (sq. in.) & 32,058 & 32,058 & 32,058 \\
\hline Xcg, (from nose) (in.) & 737.4 & 768.9 & 731.0 \\
\hline $\begin{array}{l}\text { Xh, X location of Horizontal Tail Mean } \\
\text { Aerodynamic Chord (in.) }\end{array}$ & $1,460.9$ & $1,460.9$ & $1,412.9$ \\
\hline $\begin{array}{l}\text { Xv, X location of Vertical Tail Mean } \\
\text { Aerodynamic Chord (in.) }\end{array}$ & 723.5 & 692.0 & 682.0 \\
\hline C, Mean Aerodynamic Chod of Wing (in.) & 165.4 & 165.4 & 165.4 \\
\hline B, Wing Span (in.) & $1,367.0$ & $1,367.0$ & $1,367.0$ \\
\hline Vh, Horizontal Tail Volume Coefficient & 0.832 & 0.796 & 0.784 \\
\hline Vv, Vertical Tail Volume Coefficient & 0.076 & 0.072 & 0.071 \\
\hline
\end{tabular}

The forward fuselage weight is consistent among the three concepts, as presented in Table 2. The aft fuselage of Concept \#2 has a $25 \%$ smaller wetted area (345 sq ft) than Concepts \#1 \& 2 (460 sq ft) which is consistent with the $24 \%$ lower weight. The $600 \mathrm{lb}$ increase in weight in the vertical tail in Concepts \#1 and \#2 can be attributed to the load introduced by the TCT mount which is attached to the aft spar. A negative static margin (given in Table 3) in Concept \#1 indicates that the concept is longitudinally unstable, and the loads on the horizontal tail will be higher than the stable concepts. This higher tail loading results in a significant increase in weight (1500 lb) in the horizontal tail of Concept \#1 over Concepts \#0 and \#2. Similarly, the forward shift of the CG in Concept \#2 reduces the tail load causing a decrease in horizontal tail weight and an increase in wing weight.

The large elevator deflections (given in Table 3) for trim in all three concepts suggest that the horizontal tail may be too small to trim the aircraft. As an additional check, the tail volume coefficients for the horizontal and vertical tails are computed for all three concepts. Torenbeek (Ref. 13) suggests horizontal and vertical tail volume coefficients for transport aircraft of 1.01 and 0.074 , respectively. As shown in Table 4, the vertical tail volume coefficient is within $4 \%$ of the recommended value for all concepts. The horizontal tail volume coefficient is around $20 \%$ too low. Another change that may improve the design is to increase the area of the elevator control surface (which is currently 35\% of the horizontal tail area), possibly by changing the aerodynamic deck to make the entire horizontal tail an elevator control surface (called a "floating tail”).

\section{Limitations and Planned Improvements to CDS}

Currently the CDS software is limited to generating complete FE models of low-wing aircraft with T-tails or twin-tails. However, CDS can be used to generate the components for different concepts, but the functions to generate the component interface surfaces are under development (including high-wing concepts and conventional tail concepts). The current interface function breaks the fuselage sections at the wing below the floor; therefore, a new function is needed to break the fuselage sections above the floor for a high-wing design. A similar function is needed to break the fuselage at the horizontal tail for a conventional tail concept. 
CDS 1.0 included dialog-box based input of design parameters through the PATRAN GUI. These GUI dialog boxes have not yet been adapted to work with the improved modeling functions in CDS 2.0. The GUI interface will improve the utility of CDS for casual PATRAN users.

CDS 2.0 has limited capability to correct bad input parameters. For example, the user can provide input that locates the tail and wing at the same location or even outside of the fuselage. The CDS geometry functions may actually generate usable surfaces for these parameters, but the interface and meshing routines will fail with this type of bad input. Future work on CDS will include automatic correction of such input (with GUI-based warning boxes for the user).

\section{Summary}

An innovative software (Conceptual Design Shop, CDS) for generation of complete finite element models of airframe structures has been developed. This automated process was developed as a collection of software functions written in the PATRAN command language and executed within that finite element modeling software. The software currently models low-wing aircraft with T-tails or twin tails. Two design evaluation cases were presented to evaluate typical aircraft models that can be created with CDS. The first design was a generic transport aircraft. Static and aeroelastic MSC/NASTRAN decks were generated by CDS for this design, and wing deformations agreed within $8.6 \%$. The second design was a STARC-ABL aircraft with three different tail sections. The goal of the STARC-ABL study was to evaluate the weight penalty for adding a thrust cone turbine (TCT) for boundary layer ingestion (BLI) to the aft fuselage. The three concepts were manually sized in Hypersizer. Adding the TCT to the baseline configuration increased the structural weight by $2,056 \mathrm{lb}$, and the concept was longitudinally unstable. In the third concept, it was demonstrated that narrowing the aft fuselage reduced the weight to only 289 $\mathrm{lb}$ above the weight of the baseline concept without the TCT, and this concept was longitudinally stable. It was noted that in all three designs the horizontal tail surface area seemed to be smaller than the recommended size for controlling the aircraft, resulting in large horizontal tail control surface deflections and loads.

\section{Acknowledgements}

The authors would like to thank Wu Li and Jason R. Welstead of the Aeronautics Systems Analysis Branch at NASA Langley Research Center for supplying the geometry for the generic subsonic transport and the STARC-ABL designs, respectively.

\section{References}

${ }^{1}$ Gern, F., "Update on HCDstruct - A Tool for Hybrid Wing Body Conceptual Design and Structural Optimization,” AIAA 2015-2544, January 2015.

${ }^{2}$ Laughlin, T., Corman, J., and Mavris D., “A Parametric and Physics-Based Approach to Structural Weight Estimation of the Hybrid Wing Body Aircraft,” AIAA 2013-1082, January 2013.

${ }^{3}$ Mukhopadhyay, V., Hsu, S., Mason, B. H., Sleight, D. W., Jones, W. T., Chu, J., Hicks, M. D., Spangler, J. L., Kamhawi, H., and Dahl, J. L., “Adaptive Modeling, Engineering Analysis and Design of Advanced Aerospace Vehicles,” AIAA Paper 2006-2182, 47th

AIAA/ASME/ASCE/AHS/ASC SDM Conference, Newport, Rhode Island, May 1-4, 2006. 
${ }^{4}$ Eldred, L., Padula, S., and Li, W., “Enabling Rapid and Robust Structural Analysis,” NASA/TM-2015-218687, 2015.

${ }^{5}$ RapidFEM, M4 Engineering, www.m4-engineering.com/software-creation/rapidfem [cited 2 March 2016].

${ }^{6} \mathrm{Li}, \mathrm{W}$. and Robinson, J., “Automated Generation of Finite-Element Meshes for Aircraft Conceptual Design,” AIAA Paper 2016-3287, 16th AIAA Aviation Technology, Integration, and Operations Conference, Washington, D.C., June 13-17 2016.

${ }^{7}$ Quinlan, J. R. and Gern, F. H., “Optimization of an Advanced Hybrid Wing Body Concept using HCDstruct Version 1.2,” AIAA Paper 2016-3460, 16th AIAA Aviation Technology, Integration, and Operations Conference, Washington, D.C., June 13-17 2016.

${ }^{8}$ PATRAN 2016 Release Guide, MSC Software, MSC Software, Santa Ana, CA 92707.

${ }^{9}$ MSC Software: NASTRAN Analysis Quick Reference Manual, MSC Software, Santa Ana, CA 92707.

${ }^{10}$ Mason, B. H. and Warren, Jr., J. E. "Finite Element Simulation of Three Full-Scale Crash Tests for Cessna 172 Aircraft,” AIAA Paper 2017-0633, 2017 AIAA Science and Technology Forum and Exposition, Grapevine, TX, January 2017.

${ }^{11}$ Niu, M. Airframe Structural Design, Conmilit Press Ltd., 1988.

${ }^{12}$ HyperSizer User's Manual, Book 1: Tutorial and Applications, Collier Research \& Development Corp., Hampton, VA, September 1998.

${ }^{13}$ Torenbeek, E., Synthesis of Subsonic Airplane Design, Kluwer Academic Publishers, Dordrecht, NL. 1987. 